\title{
Spatial optical transmitter based on on/off keying line coding modulation scheme for optimum performance of telecommunication systems
}

\author{
Hazem M. El-Hageen ${ }^{1}$, Aadel M. Alatwi ${ }^{2}$, Ahmed Nabih Zaki Rashed ${ }^{3}$ \\ 1,2Electrical Engineering Department, University of Tabuk, Saudi Arabia \\ ${ }^{1}$ Egyptian Nuclear \& Radiological Regulatory Authority, Egypt \\ ${ }^{3}$ Electronics and Electrical Communications Engineering Department, Menoufia University, Egypt
}

\begin{tabular}{l}
\hline \hline Article Info \\
\hline Article history: \\
Received Apr 11, 2020 \\
Revised Jul 8, 2020 \\
Accepted Jul 15, 2020 \\
\hline
\end{tabular}

\section{Keywords:}

Line coding

On off keying

Optimum performance

Signal gain

Telecommunication system

\begin{abstract}
This study has presented a spatial optical transmitter based on on off keying line coding modulation scheme for the optimum performance of telecommunication systems. The encircled flux versus fiber core radius, the 3D graph for fiber mode versus core radius, and the signal power level in $\mathrm{dBm}$ versus wavelength through coarse wavelength division multiplexing with a fiber length of $20 \mathrm{~km}$ are presented and discussed in detail. The total power measured in $\mathrm{W}$ and $\mathrm{dBm}$ as well as the signal power amplitude level obtained through the infinite impulse response (IIR) filter based on both $\mathrm{Z}$ domain and pole/zero coefficient filter types are illustrated clearly. Signal gain, noise figure, maximum $\mathrm{Q}$ factor, and received power are also clarified against bit rates for various modulation line coding schemes.
\end{abstract}

This is an open access article under the CC BY-SA license.

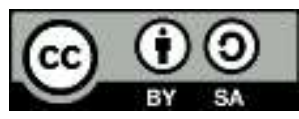

\section{Corresponding Author:}

Ahmed Nabih Zaki Rashed

Faculty of Electronic Engineering,

Menoufia University

Gamal Abd El-Nasir, Qism Shebeen El-Kom

Shibin el Kom, Menofia Governorate, Egypt

E-mail: zakirashed73355@gmail.com

\section{RELATED WORKS}

The information revolution is geared towards presenting, analyzing, and transporting information with high efficiency. It relies on communication networks to transport information while computers are used to present, analyze, and process data. Today, various data types are transmitted over communications networks, namely, text, audio, images, computer data, videos, and so on. Therefore, the network must be equipped with the requirements of all types of information and the communication networks must be independent of the information type [1-6]. The networks that support various information types are called multimedia networks. Huge amounts of high-speed multimedia data are being produced, so the design of multimedia networks must be capable of handling this. Among the most important specifications that must be met is the high bit rate for real-time video services [7-12].

Optical fiber links comprise the best solution for implementing multimedia networks for fixed user locations. The development of manufacturing technology for detectors and light sources has attracted considerable attention, as they are key to the development of optical communication systems [13-19]. The use of fiber to implement local area networks (LANs) has increased. Consequently, common LANs such as Ethernet, token bus, token ring, and star have been implemented using optical fiber, which bestows numerous 
advantages. When the signal is optoelectronically regenerated or amplified [20-28], the network is classified as an active broadcast network such as a token ring; otherwise, it is a passive broadcast network such as an Ethernet or a token bus [29-37].

\section{MODEL DESCRIPTION AND RESEARCH METHOD}

Figure 1 shows the proposed simulation model for this study. User-defined sequence generators generate a stream of bits, and all the bits are encoded with a hyperbolic secant pulse generator. The spatial optical transmitter has the following technical specifications: frequency $=1550 \mathrm{~nm}$, power $=0 \mathrm{dBm}$, on off keying modulation type, power ratio array $=1$, extinction ratio $=10 \mathrm{~dB}$, and linewidth $=10 \mathrm{MHz}$. The interaction between the encoded electrical signal and the light signal happens through $\mathrm{LiNbO}_{3}$ modulators.

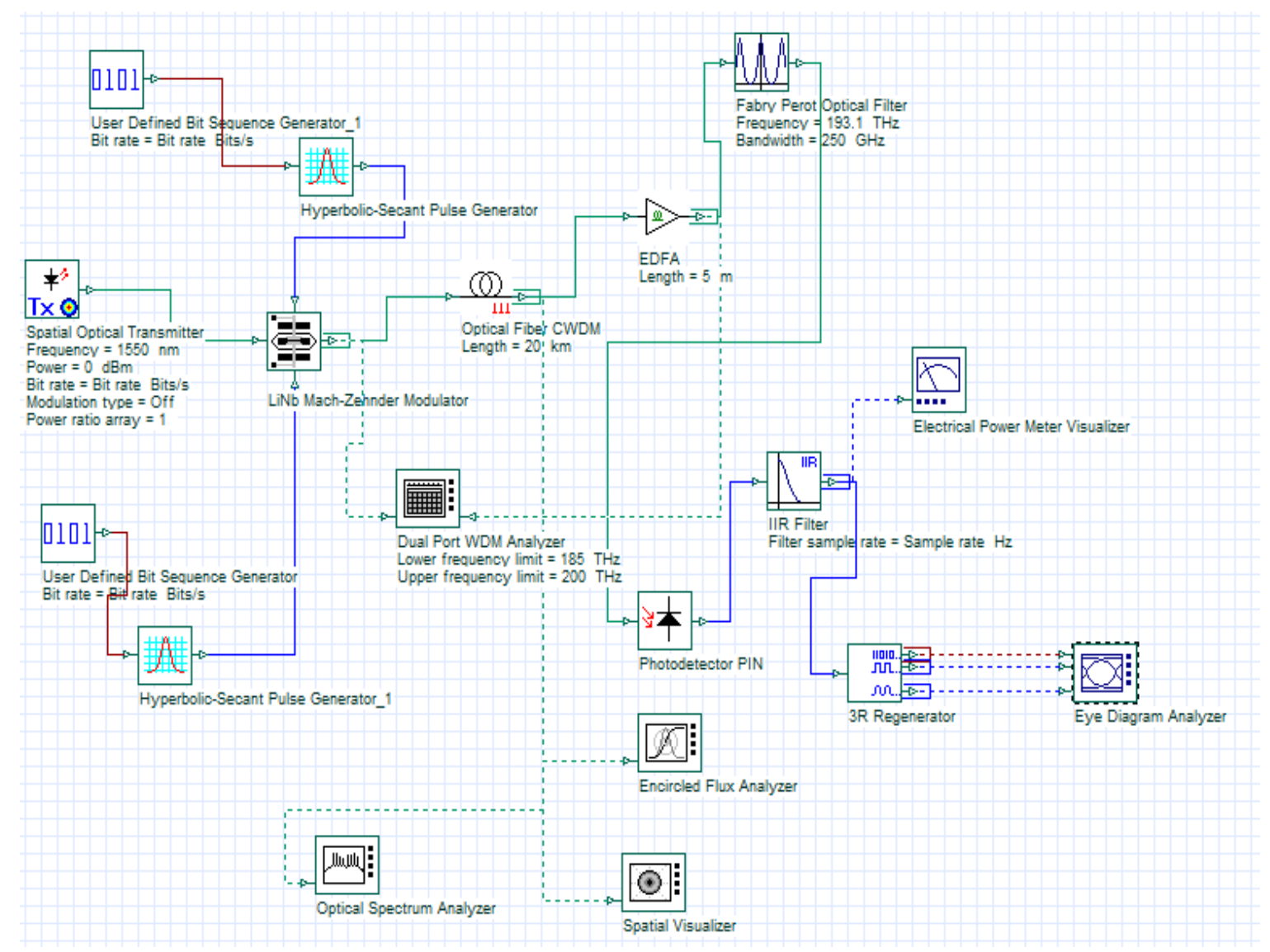

Figure 1. The simulation model for this study

These modulators are used to modulate the electro-optic signals. The modulated signal is directed to the coarse wavelength division multiplexing (CWDM) with a fiber length of $20 \mathrm{~km}$. The signal power, noise power, input/output light signal-to-noise ratio, signal gain, and noise figure are determined using the dualport WDM analyzer. EDFA is used to compensate for the losses due to the attenuation in the fiber cable. Fabry-Perot light filters are used to filter the original signal from any unwanted noise parts. The Fabry-Perot light filters have the following technical specifications: frequency $=193.1 \mathrm{THz}$, bandwidth $=250 \mathrm{GHz}$, and free spectral range $=500 \mathrm{GHz}$. The light PIN photo-detectors convert the light signal to electrical form, which it is later filtered by the infinite impulse response (IIR) filter. The encircle flux analyzer measures the electric field distribution with the fiber core radius. The spatial visualizer measures the available number of modes in the fiber with its configuration. The signal power level is measured with the time period by an optical spectrum analyzer. 


\section{PERFORMANCE ANALYSIS WITH DISCUSSIONS}

The maximum $\mathrm{Q}$ factor, minimum BER, and received power are measured through the BER analyzer and the optical power meters, respectively. Based on the data in Table 1, the simulation results are measured and clarified. Moreover, the encircle flux analyzer measures the electric field distribution with the fiber core radius. The spatial visualizer measures the available number of modes in the fiber with its configuration.

Table 1. Variables used in this work

\begin{tabular}{cc}
\hline Variables & Value/Unit \\
\hline Frequency & $193.1 \mathrm{THz}$ \\
Power & $0 \mathrm{dBm}$ \\
Transmission bit rate & $10 \mathrm{~Gb} / \mathrm{s}, 40 \mathrm{~Gb} / \mathrm{s}, 100 \mathrm{~Gb} / \mathrm{s}$ \\
Extinction ratio & $10 \mathrm{~dB}$ \\
Fiber optic CWDM length & $20 \mathrm{~km}$ \\
EDFA amplifier length & $5 \mathrm{~m}$ \\
Optical filter bandwidth & $250 \mathrm{GHz}$ \\
PIN receiver responsivity & $1 \mathrm{~A} / \mathrm{W}$ \\
PIN receiver dark current & $10 \mathrm{nA}$ \\
\hline
\end{tabular}

Figure 2 shows the signal power level in $\mathrm{dBm}$ versus wavelength through the CWDM with a fiber length of $20 \mathrm{~km}$. The maximum signal power is $-9.78205 \mathrm{dBm}$ while the minimum noise power is -104.296 $\mathrm{dBm}$. Figure 3 presents the encircled flux versus the fiber core radius through the CWDM with a fiber length of $20 \mathrm{~km}$. At a fiber core radius of $2 \mu \mathrm{m}$, the encircled flux reaches $20 \%$ but at a fiber core radius of $8 \mu \mathrm{m}$, the encircled flux reaches $80 \%$. In addition, at fiber core radii of $10 \mu \mathrm{m}$ and $20 \mu \mathrm{m}$, the encircled flux reaches $100 \%$. Figure 4 demonstrates the 3D graph for fiber mode versus core radius through the CWDM fiber with a length of $20 \mathrm{~km}$. The mode field Gaussian intensity distribution through the fiber core radius is from $10 \mu \mathrm{m}$ to $20 \mu \mathrm{m}$ from the $\mathrm{x}$ axis. The polar power polarization in the $\mathrm{x}$ direction is shown in Figure 4 .

Figure 5 indicates the total power measured in $\mathrm{W}$ and $\mathrm{dBm}$ through the IIR filter based on the $\mathrm{Z}$ domain coefficient filter type. The total power is $277.158 \mu \mathrm{W}$ or $-6.437 \mathrm{dBm}$. Figure 6 demonstrates the total power measured in $\mathrm{W}$ and $\mathrm{dBm}$ through the IIR filter based on the pole/zero coefficient filter type. The total power is $544.784 \mu \mathrm{W}$ or $-2.638 \mathrm{dBm}$.

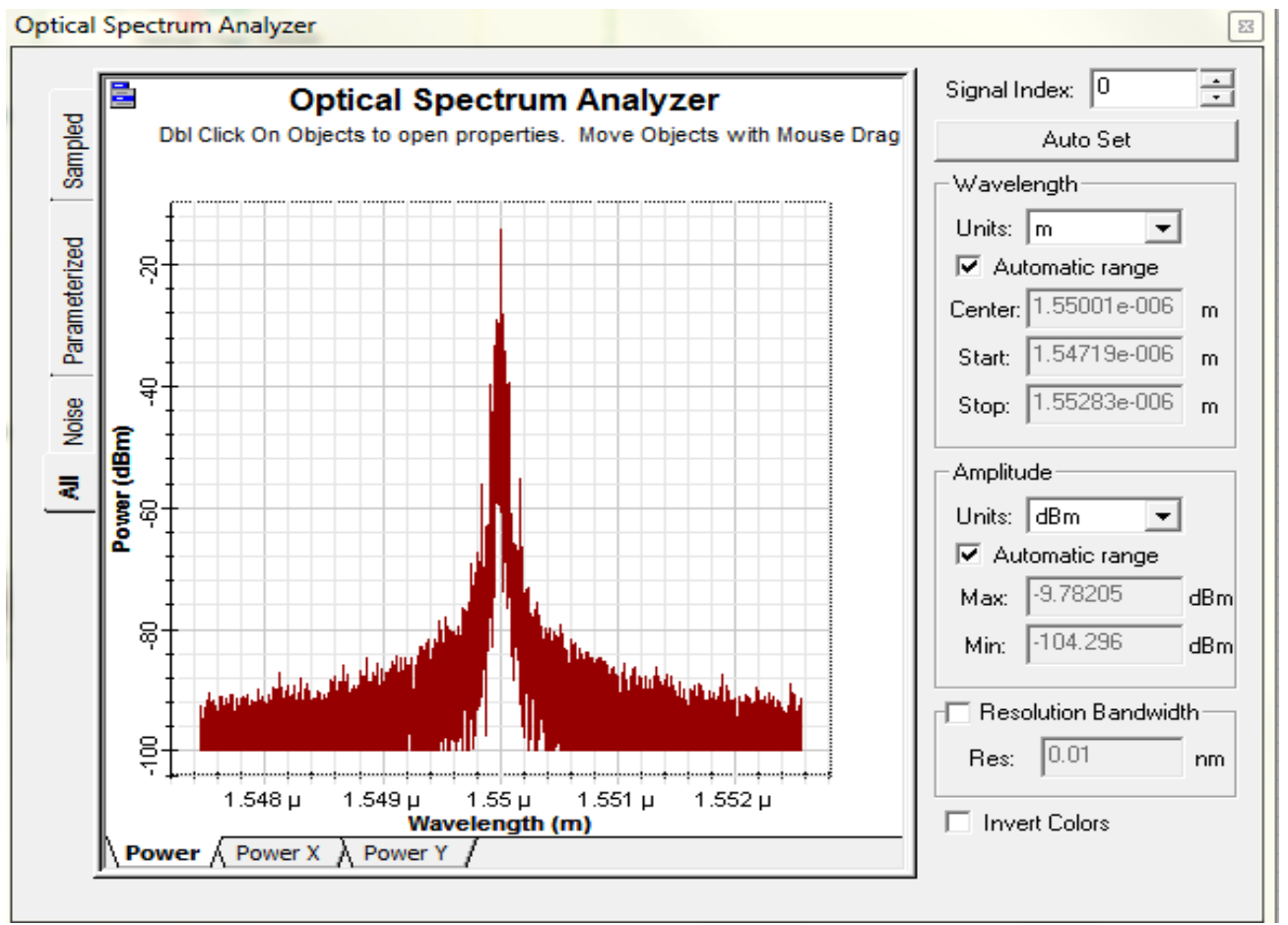

Figure 2. The signal power level in $\mathrm{dBm}$ versus wavelength through the CWDM fiber with a length of $20 \mathrm{~km}$ 


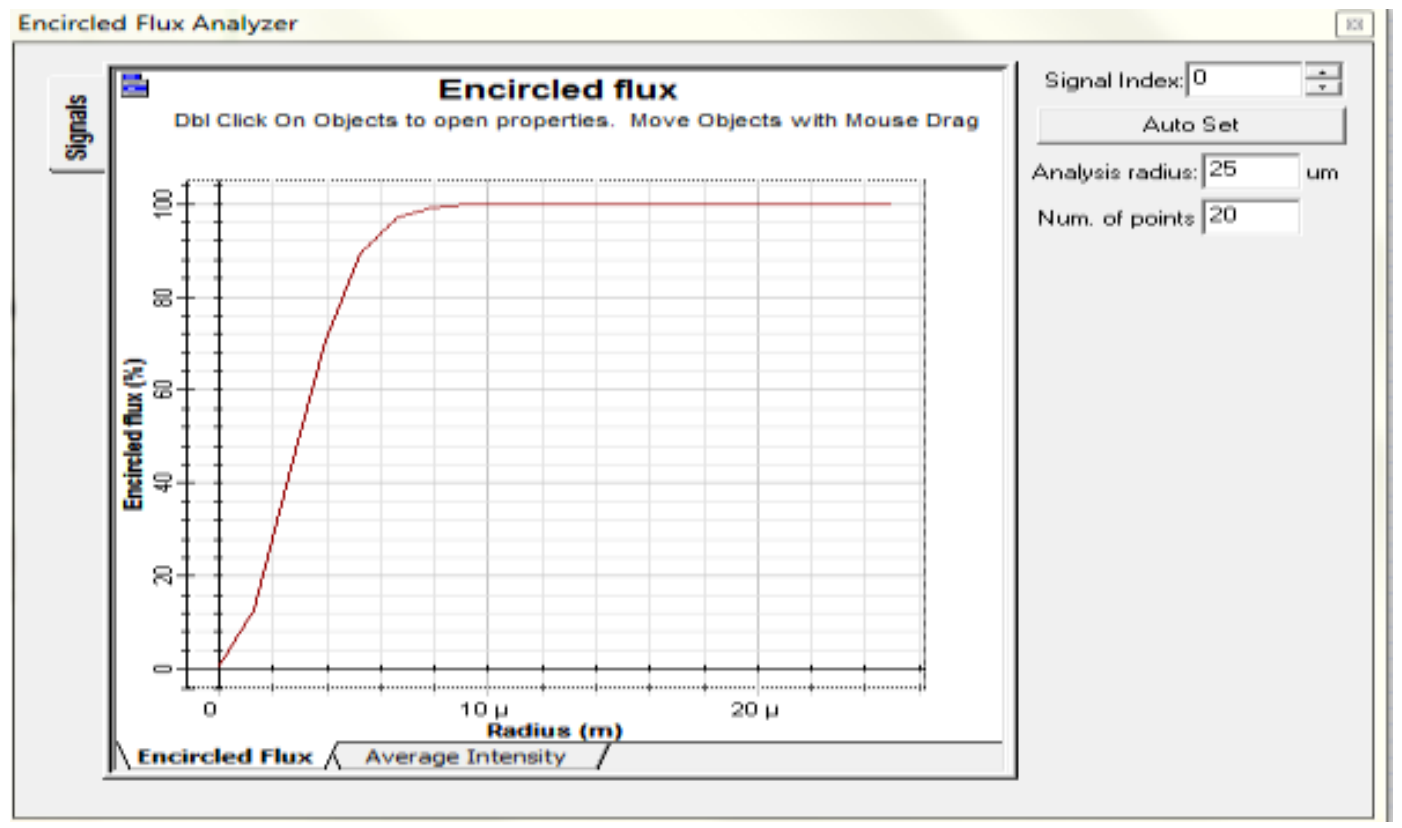

Figure 3. The encircled flux versus fiber core radius through the CWDM fiber with a length of $20 \mathrm{~km}$

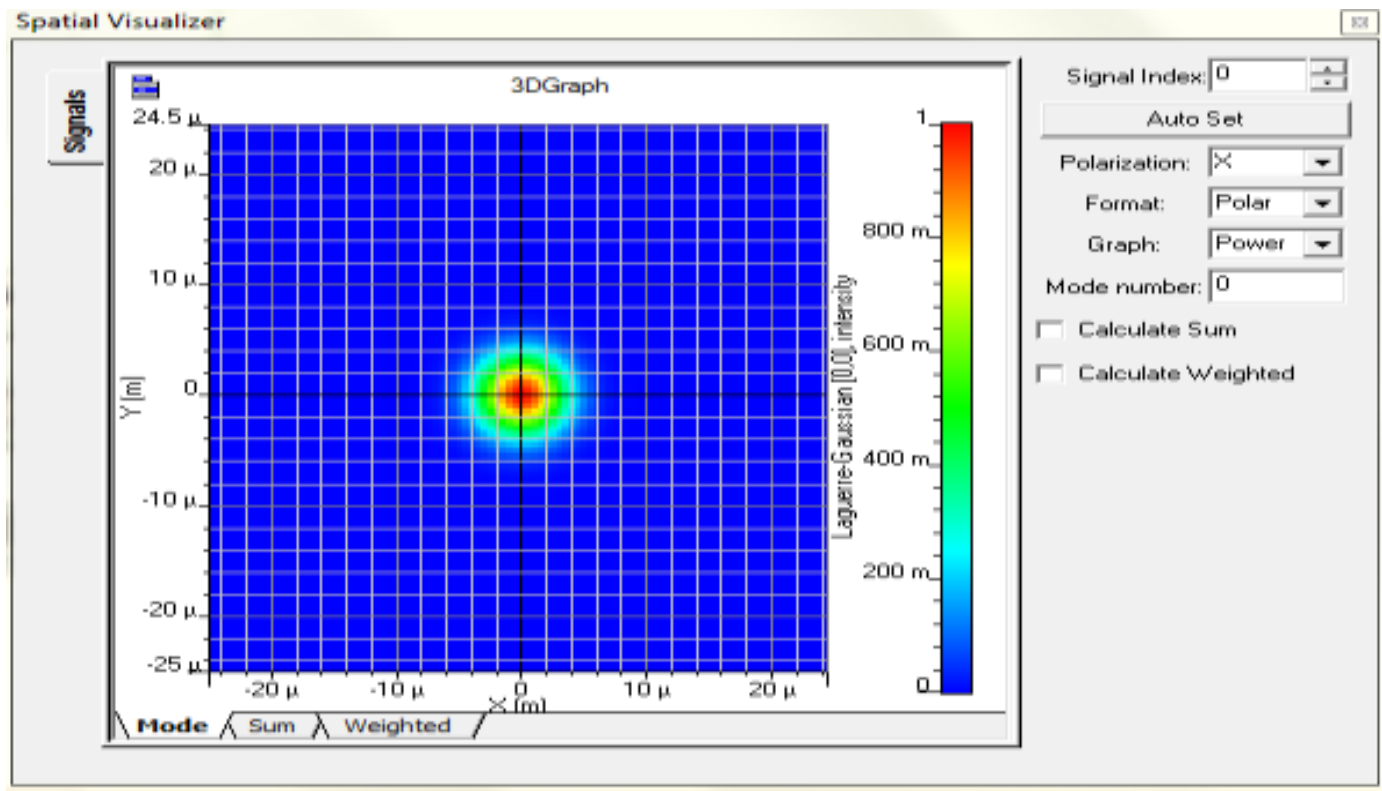

Figure 4. The 3D graph for fiber mode configuration versus core radius through the CWDM fiber with a length of $20 \mathrm{~km}$

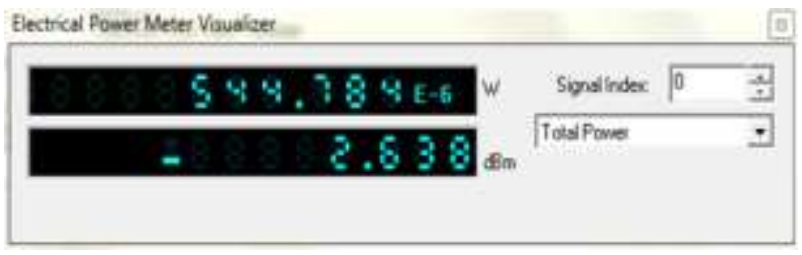

Figure 5. The total power measured in $\mathrm{W}$ and $\mathrm{dBm}$ through the IIR filter based on $\mathrm{Z}$ domain coefficient filter type

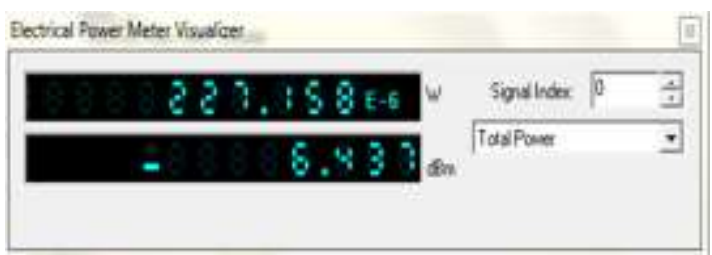

Figure 6. The total power measured in $\mathrm{W}$ and $\mathrm{dBm}$ through the IIR filter based on pole/zero coefficient filter type 
Figure 7 and Figure 8 show the signal power amplitude level through the IIR filter based on both Z domain and pole/zero coefficient filter types. Based on the $\mathrm{Z}$ domain coefficient filter type, the maximum $\mathrm{Q}$ factor is 13.44 and the minimum BER is $1.59 \times 10^{-44}$; these results are obtained using the IIR filter (Figure 7). Meanwhile, based on the pole/zero coefficient filter type, the maximum Q factor is 14.216 and the minimum BER is $3.44 \times 10^{-46}$; these results are obtained using the IIR filter (Figure 8).

Figure 9 presents the signal gain against transmission data rate for different line coding schemes. For on-off line coding, the signal gain is $27.65 \mathrm{~dB}$ at $10 \mathrm{~Gb} / \mathrm{s}, 13.46 \mathrm{~dB}$ at $40 \mathrm{~Gb} / \mathrm{s}$, and $9 \mathrm{~dB}$ at $100 \mathrm{~Gb} / \mathrm{s}$. Meanwhile, for NRZ line coding, the signal gain is $24.65 \mathrm{~dB}$ at $10 \mathrm{~Gb} / \mathrm{s}, 9.54 \mathrm{~dB}$ at $40 \mathrm{~Gb} / \mathrm{s}$, and $4.765 \mathrm{~dB}$ at $100 \mathrm{~Gb} / \mathrm{s}$. As the transmission bit rate increases, the signal gain decreases.
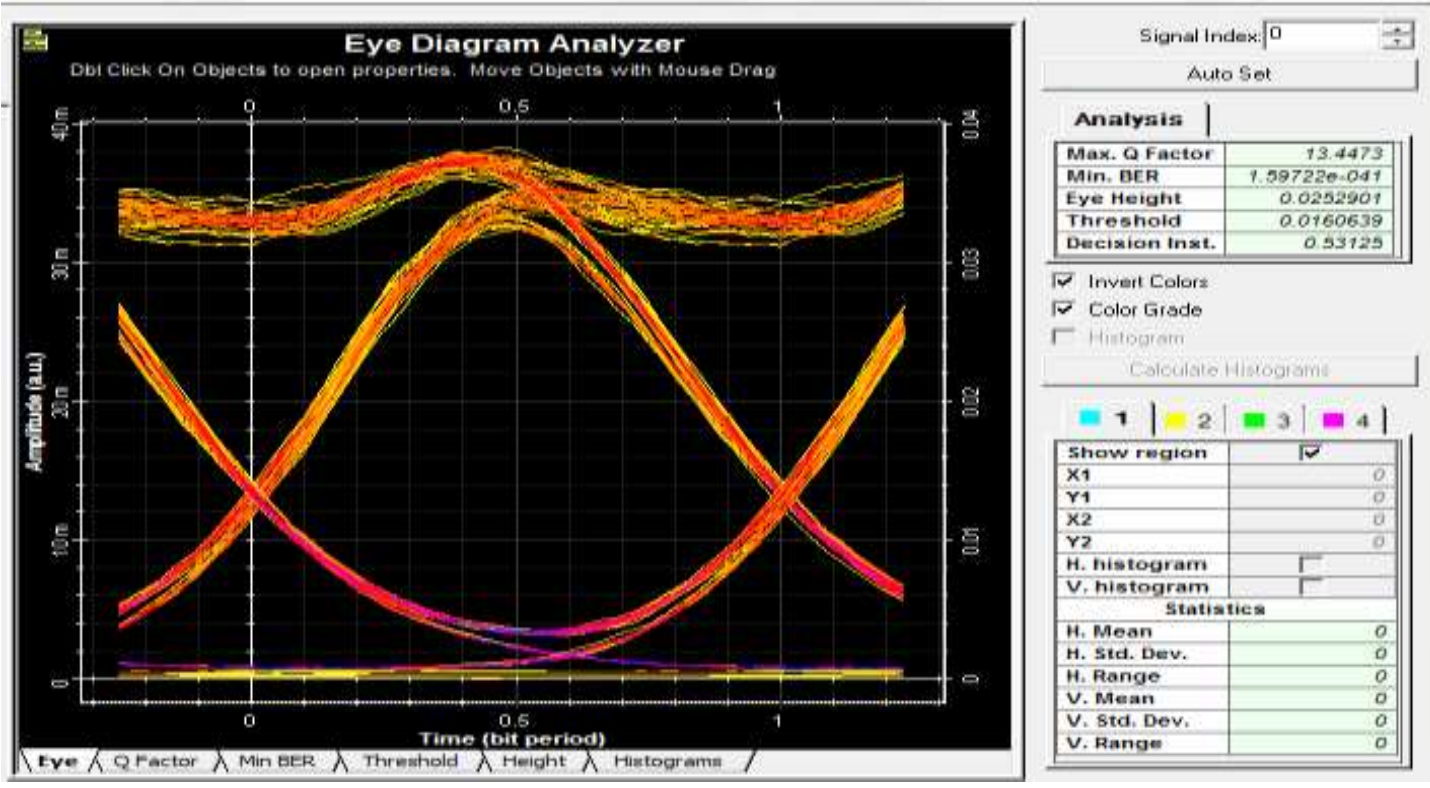

Figure 7. The signal power amplitude level through the IIR filter based on $\mathrm{Z}$ domain coefficient filter type
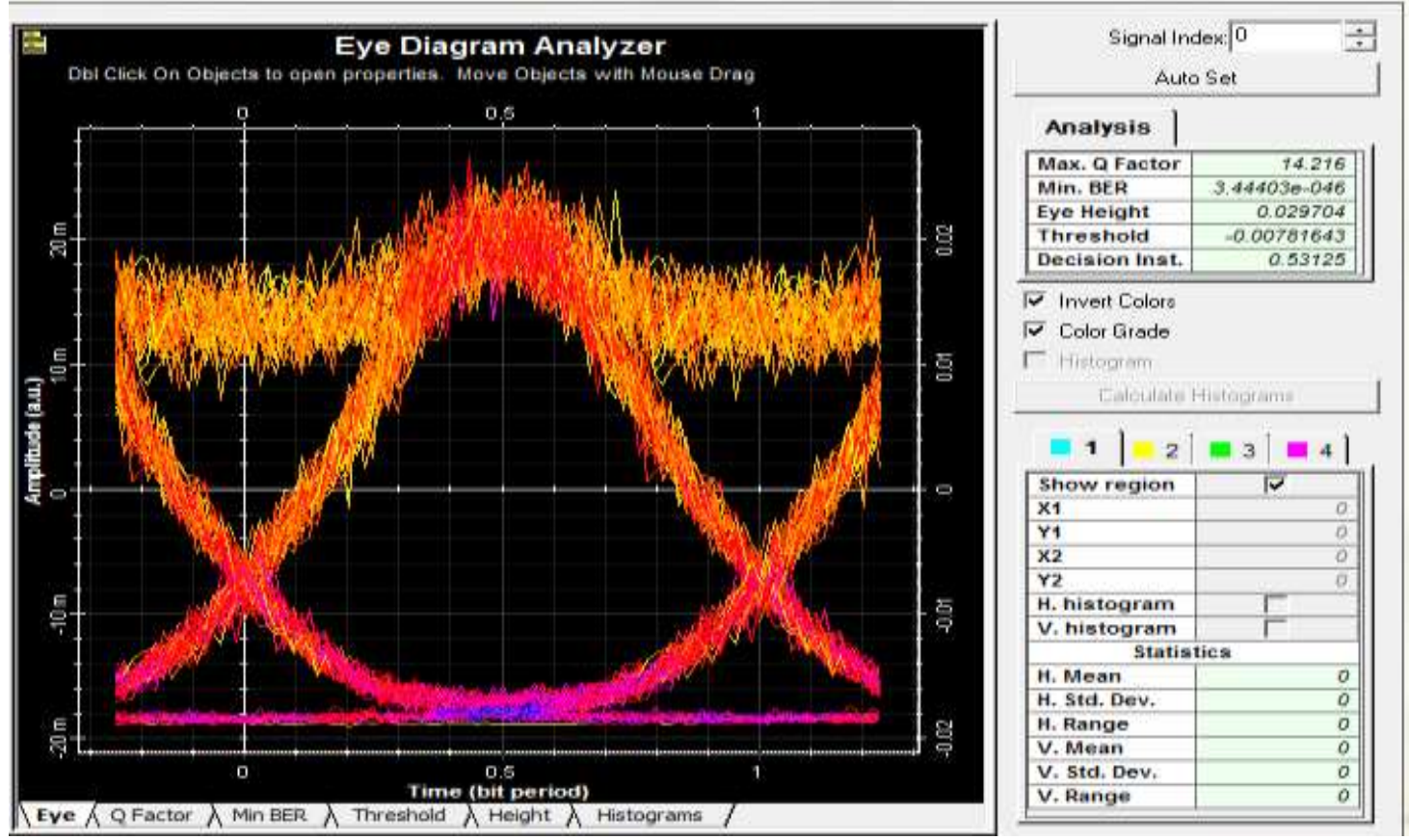

Figure 8. The signal power amplitude level through the IIR filter based on pole/zero coefficient filter type 


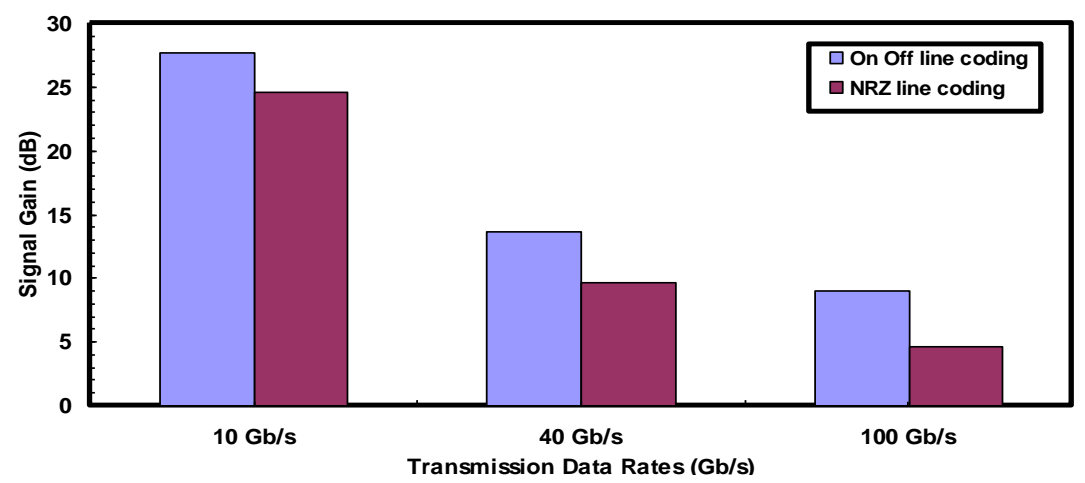

Figure 9. The signal gain against transmission data rate for different line coding schemes

Figure 10 indicates the noise figure against the transmission data rate for different line coding schemes. For on-off line coding, the noise figure is $1.12 \mathrm{~dB}$ at $10 \mathrm{~Gb} / \mathrm{s}, 2.56 \mathrm{~dB}$ at $40 \mathrm{~Gb} / \mathrm{s}$, and $4 \mathrm{~dB}$ at 100 $\mathrm{Gb} / \mathrm{s}$. Meanwhile, for NRZ line coding, the noise figure is $3.765 \mathrm{~dB}$ at $10 \mathrm{~Gb} / \mathrm{s}, 5 \mathrm{~dB}$ at $40 \mathrm{~Gb} / \mathrm{s}$, and $7 \mathrm{~dB}$ at $100 \mathrm{~Gb} / \mathrm{s}$. As the transmission bit rate increases, the noise figure increases.

Figure 11 presents the maximum $\mathrm{Q}$ factor against the transmission data rate for different line coding schemes. For on-off line coding, the maximum Q factor is 13.44 at $10 \mathrm{~Gb} / \mathrm{s}, 4.88$ at $40 \mathrm{~Gb} / \mathrm{s}$, and 1.65 at 100 $\mathrm{Gb} / \mathrm{s}$. Meanwhile, for NRZ line coding, the maximum Q factor is 10.23 at $10 \mathrm{~Gb} / \mathrm{s}, 3.12$ at $40 \mathrm{~Gb} / \mathrm{s}$, and 0.6754 at $100 \mathrm{~Gb} / \mathrm{s}$. As the transmission bit rate increases, the maximum $\mathrm{Q}$ factor decreases.

Figure 12 shows the received power against the transmission data rate for different line coding schemes. For on-off line coding, the received power is $0.666 \mu \mathrm{W}$ at $10 \mathrm{~Gb} / \mathrm{s}, 0.49 \mu \mathrm{W}$ at $40 \mathrm{~Gb} / \mathrm{s}$, and 0.44 $\mu \mathrm{W}$ at $100 \mathrm{~Gb} / \mathrm{s}$. Meanwhile, for NRZ line coding, the received power is $0.646 \mu \mathrm{W}$ at $10 \mathrm{~Gb} / \mathrm{s}, 0.489 \mu \mathrm{W}$ at $40 \mathrm{~Gb} / \mathrm{s}$, and $0.4 \mu \mathrm{W}$ at $100 \mathrm{~Gb} / \mathrm{s}$. As the transmission bit rate increases, the received power decreases.

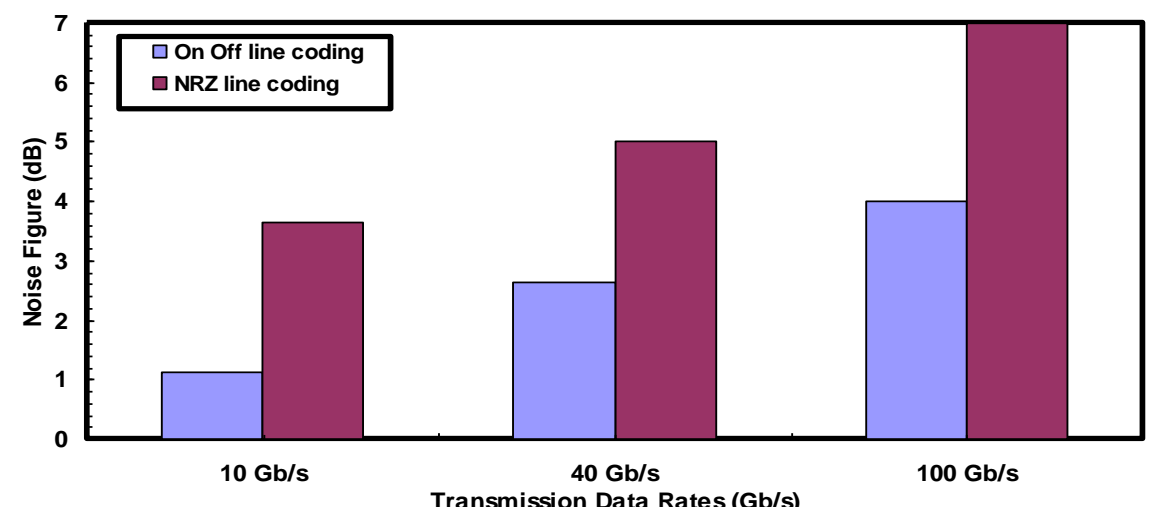

Figure 10. The noise figure against transmission data rate for different line coding schemes

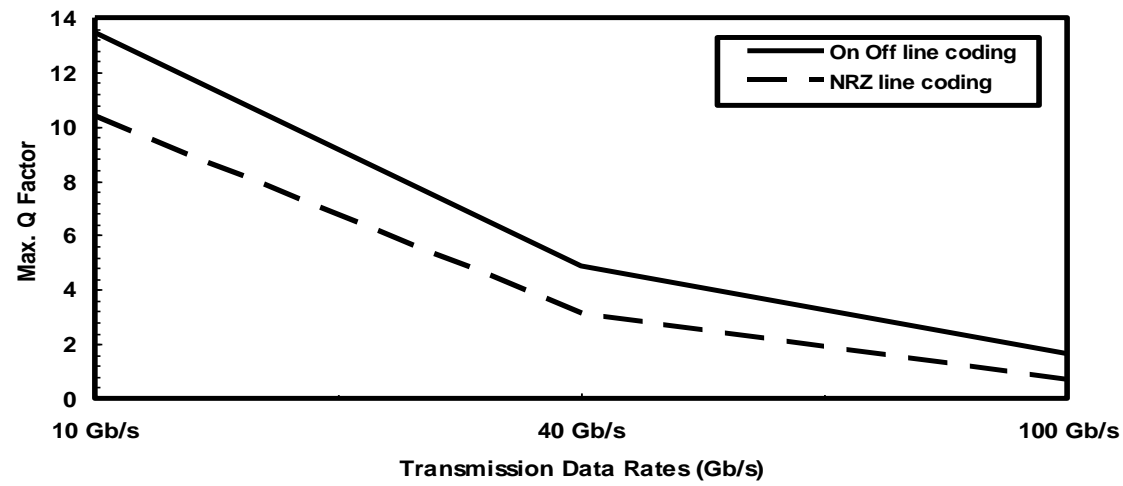

Figure 11. Max. The maximum $Q$ factor against transmission data rate for different line coding schemes 


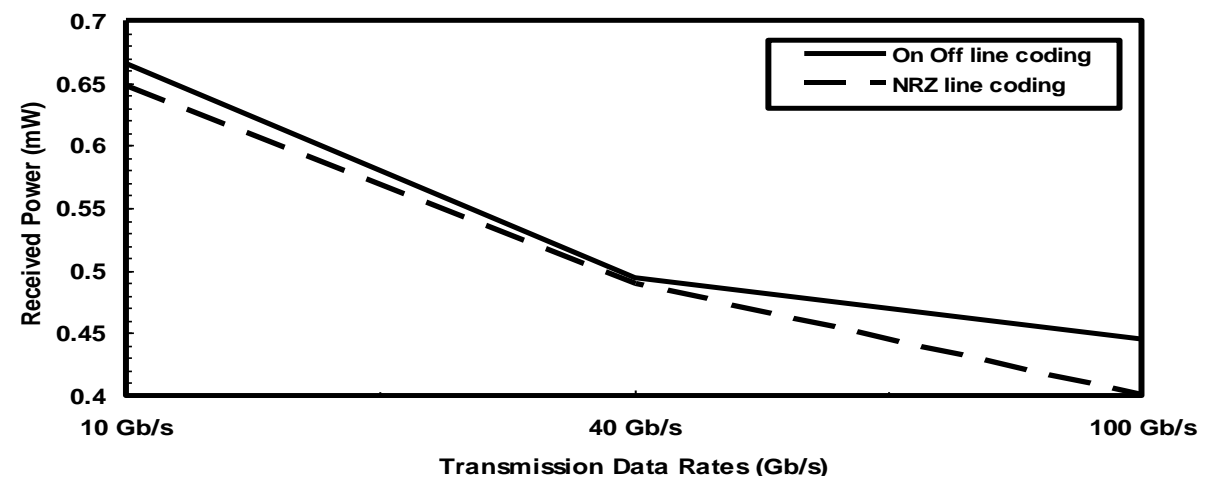

Figure 12. The received power against transmission data rate for different line coding schemes

\section{CONCLUSION}

We have simulated an on-off line coding modulation technique for a spatial optical transmitter through a CWDM fiber with a length of $20 \mathrm{~km}$ for the optimum performance of telecommunication broadcasting systems. The optimum transmission data rates are achieved at $40 \mathrm{~Gb} / \mathrm{s}$ with acceptable maximum $\mathrm{Q}$ factor, minimum BER, maximum signal gain, minimum noise figure, and maximum received power. The signal power amplitude level and total power are measured through the IIR filter based on both $\mathrm{Z}$ domain and pole-zero coefficient filter types. The encircled flux and 3D graph for fiber mode configuration versus core radius through a CWDM fiber with a length of $20 \mathrm{~km}$ are also clarified in the graphs.

\section{REFERENCES}

[1] M. Zhao, et al., "Analysis and optimization of intensity noise reduction in spectrum-sliced WDM systems using a saturated semiconductor optical amplifier," IEEE Photon. Tech. Lett., vol. 14, no. 3, pp. 390-392, 2002.

[2] F. Öhman, et al., "Noise and regeneration in semiconductor waveguides with saturable gain and absorption," IEEE J. Quantum Electron., vol. 40, no. 3, pp. 245-255, 2004.

[3] M. Menif, et al., "Error free transmission for incoherent broadband optical communications systems using incoherent-to-coherent wavelength conversion," IEEE J. Lightw. Technol., vol. 23, no. 1, pp. 287-294, 2005.

[4] A. Gupta, "Comparative analysis of various wavelength division multiplexed PON standards," Journal of Optical Communications, vol. 40, no. 1, pp. 51-54, 2019.

[5] J. Mork, et al., "The dynamics of semiconductor optical amplifiers: Modeling and applications," Optics \& Photonics News, vol. 14, no. 7, pp. 42-48, 2003.

[6] H. Kim, et al., "A gain-clamped SOA with distributed Bragg reflectors fabricated under both ends of active waveguide with different lengths," IEEE Photonics Technology Letters, vol. 16, no. 4, pp. 999-1001, 2004.

[7] E. S. Björlin, et al., "Carrier-confined vertical-cavity semiconductor optical amplifiers for higher gain and efficiency,” IEEE J. Select. Topics Quantum Electron., vol. 9, no. 5, pp. 1374-1385, 2003.

[8] Y. Said, et al., "Analysis of noise effects in long semiconductor optical amplifiers," The Open Optics Journal, vol. 2, pp. 61-66, 2008.

[9] E. S. Björlin, et al., "Optically preamplified receiver at $10 \mathrm{~Gb} / \mathrm{s}$ using a vertical cavity SOA," Electron. Lett., vol. 37, no. 24, pp. 1474-1475, 2001.

[10] F. Öhman, et al., "Noise and regeneration in semiconductor waveguides with saturable gain and absorption," IEEE J. Quantum Electron., vol. 40, no. 3, pp. 245-255, 2004.

[11] S. Iyer, S. P. Singh, "Effect of channel spacing on the design of mixed line rate optical wavelength division multiplexed networks," Journal of Optical Communications, vol. 40, no. 1, pp. 75-82, 2019.

[12] IS Amiri, et al., "Interaction between optical sources and optical modulators for high-speed optical communication networks," Journal of Optical Communications, 2019.

[13] IS Amiri, et al., "Effects of order super gaussian pulses on the performance of high data rate optical fiber channel in the presence of self phase modulation," Journal of Optical Communications, 2019.

[14] IS Amiri, et al., "Mathematical model analysis of dispersion and loss in photonic crystal fibers," Journal of Optical Communications, 2019.

[15] IS Amiri, et al., "Basic functions of fiber bragg grating effects on the optical fiber systems performance efficiency," Journal of Optical Communications, 2019.

[16] IS Amiri, et al., "Nonlinear effects with semiconductor optical amplifiers," Journal of Optical Communications, Vol. 0, Issue 0, 2019.

[17] IS Amiri, et al., "High-speed light sources in high-speed optical passive local area communication networks," Journal of Optical Communications, 2019. 
[18] V. R. Miriampally, T. Hailu, "2D single mode optical fiber wave guide design for multi haul applications," International Journal of Innovative Research in Electronics and Communications (IJIREC), vol. 3, no. 5, pp. 24-35, 2016,

[19] F. E. Seraji, R. Kiaee, "A revisit of refractive index profiles design for reduction of positive dispersion, splice loss, and enhancement of negative dispersion in optical transmission lines," International Journal of Optics and Applications, vol. 4, no. 2, pp. 62-67, 2014.

[20] S. A. Bhuiyan, "design, simulation, performance analysis and optimization process of MMGRIN fiber with RI distribution," Ist International conference on Electrical \& Communication Engineering and Renewable Energy, pp. 1-6, 2014.

[21] M. Artiglia, "Mode field diameter measurements in single mode optical fibers, " Journal of Lightwave Tech., vol. 7, no. 8, pp. 1139-1152, 1989.

[22] V. Palodiya, S. K. Raghuwanshi, "Dispersion characteristics of novel class multi clad dispersion shifted hollow core fibers for WDM optical systems," Indian Journal of Pure \& Applied Physics, vol. 56, no. 1, pp. 76-79, 2018.

[23] C. Kromer, et al., "A low-power 20-GHz 52-dB transimpedance amplifier in 80-nm CMOS," IEEE Journal of Solid State Circuits, vol. 39, no. 6, pp. 885-894, 2004.

[24] D. Praveen, et al., "A comparative analysis of transimpedance amplifier in giga-bit optical communication," Research Journal of Engineering Sciences, vol. 3, no. 3, pp. 6-9, 2014.

[25] Lucas M. Riob, et al., "Wideband transimpedance amplifiers for optoelectronics: Applications to dynamic interferometry," Revista elektron, vol. 1, no. 1, pp. 16-22, 2017.

[26] L. Safar, M. S. Zaki, "design and simulation of differential transimpedance amplifier (TIA) based on $0.18 \mu \mathrm{m}$ CMOS technology,” Al-Rafidain Engineering, vol. 21, no. 4, pp. 121-130, 2013.

[27] X. Hui, et al., "A 3.125-Gb/s inductor less transimpedance amplifier for optical communication in $0.35 \mu \mathrm{m}$ CMOS," Journal of Semiconductors, vol. 32, no. 10, 2011.

[28] S. Subi, and G. b. Lakshmi, "Optical solitons simulation using DSF and optical pulse generator in single mode optical fiber," International Journal of Science and Research (IJSR), ISSN (Online): 2319-7064, vol. 4, no. 2, pp. 254-258, 2015.

[29] M. Arora and G. Pandove, "Simulated circuit for generation of $40 \mathrm{GHz}$ soliton train," International Journal of Emerging Trends in Electrical and Electronics, vol. 5, no. 2, pp. 73-76, 2013.

[30] A. C. Kadhim, "Simulation and evaluation of soliton signal effects in fiber optics," Iraqi Journal of Science, vol. 54, Supplement no. 4, pp.1108-1114, 2013.

[31] IS Amiri, et al., "Z Shaped like resonator with crystal in the presence of flat mirror based standing wave ratio for optical antenna systems," Indonesian Journal of Electrical Engineering and Computer Science, vol. 17, no. 3, pp. 1405-1409, 2020,

[32] IS Amiri, et al., "Influence of device to device interconnection elements on the system behavior and stability," Indonesian Journal of Electrical Engineering and Computer Science (IJEECS), vol. 18, no. 2, pp. 843-847, 2020,

[33] Ahmed Nabih Zaki Rashed, et al., "Dental lasers applications in visible wavelength operational band," Indonesian Journal of Electrical Engineering and Computer Science (IJEECS), vol. 18, no. 2, pp. 890-895, 2020,

[34] IS Amiri, et al., "Comparative simulation study of multi stage hybrid all optical fiber amplifiers in optical communications," Journal of Optical Communications, 2020.

[35] IS Amiri, et al., "Optical communication transmission systems improvement based on chromatic and polarization mode dispersion compensation simulation management," Optik Journal, vol. 207, 2020.

[36] Ahmed Nabih Zaki Rashed, et al., "Distributed feedback laser (DFB) for signal power amplitude level improvement in long spectral band," Journal of Optical Communications, 2020,

[37] IS Amiri, et al., "Analytical model analysis of reflection/transmission characteristics of long-period fiber bragg grating (LPFBG) by using coupled mode theory," Journal of Optical Communications, 2020. 